\title{
Produção de poli(3-hidroxibutirato) por Cupriavidus necator em batelada alimentada usando glicerol
}

\section{Poly(3-hydroxybutyrate) production synthesized by Cupriavidus necator on fed-batch culture using glycerol}

\author{
Bruna Regina Sombrio ${ }^{*}$, Andréa Lima dos Santos Schneider ${ }^{1}$, Ana Paula Testa Pezzin ${ }^{1}$, Giannini Apati² \\ e Tamiris Schroeder ${ }^{2}$
}

\author{
${ }^{1}$ Programa de Mestrado em Engenharia de Processos, Universidade da Região de Joinville - UNIVILLE, \\ Joinville, SC, Brasil \\ 2Departamento de Engenharia Química, Universidade da Região de Joinville - UNIVILLE, \\ Joinville, SC, Brasil \\ *bruna.rsombrio@gmail.com
}

\begin{abstract}
Resumo
Poli(3-hidroxibutirato) $[\mathrm{P}(3 \mathrm{HB})]$ é um poliéster natural, biodegradável e é considerado um substituto atrativo para polímeros petroquímicos, pois tem a vantagem de ser degradado em solo dentro de alguns meses por micro-organismos. Este trabalho explora três estratégias para sintetizar $\mathrm{P}(3 \mathrm{HB})$ a partir de Cupriavidus necator tendo glicerol como cosubstrato: cultivo sem glicerol, com adição de $20 \mathrm{~g} \mathrm{~L}^{-1}$ de glicerol na fase de produção do polímero e $20 \mathrm{~g} \mathrm{~L}{ }^{-1}$ de glicerol no início do cultivo, a fim de avaliar o seu efeito sobre o crescimento celular e a síntese do polímero. Os resultados mostraram que a adição de glicerol no início do cultivo conduziu a maiores valores de percentagem de acúmulo de $\mathrm{P}(3 \mathrm{HB})(64,12 \%)$. No entanto, nos experimentos sem glicerol podem ser observados maiores valores para fator de conversão em substrato $\left(0,17 \mathrm{~g} \mathrm{~g}^{-1}\right)$. Esses parâmetros apresentaram diferenças estatisticamente significativas em função da estratégia de cultivo utilizado.
\end{abstract}

Palavras-chave: polímero biodegradável, biossintese, glicerol, poli(hidroxialcanoato).

\begin{abstract}
Poly(3-hydroxybutyrate $)[\mathrm{P}(3 \mathrm{HB})]$ is a natural, biodegradable polyester and is considered an attractive substitute for the petrochemical polymers, because has advantage of being degraded in the soil within a few months by microorganisms. This work exploits three strategies to synthesize $\mathrm{P}(3 \mathrm{HB})$ from of the Cupriavidus necator with glycerol as co-substrate: cultivation without glycerol, with addition of $20 \mathrm{~g} \mathrm{~L}^{-1}$ glycerol in the phase of polymer producing and addition of $20 \mathrm{~g} \mathrm{~L}^{-1}$ of glycerol at the start of cultivation, in order to evaluate its effect on cell growth and the synthesis of the polymer. The results showed that the addition of glycerol at the start of culture led to highest values of accumulation percentage the $\mathrm{P}(3 \mathrm{HB})(64.12 \%)$. However, in the experiments without glycerol can be observed higher values toward biomass to substrate yield $\left(0.17 \mathrm{~g} \mathrm{~g}^{-1}\right)$. These parameters presented statistically significant differences in function of the cultivation strategy used.
\end{abstract}

Keywords: biodegradable polymer, biosynthesis, glycerol, poly(hydroxyalcanoate).

\section{Introdução}

Os polímeros sintéticos tornaram-se importantes na sociedade porque podem substituir materiais como: papel, madeira, vidro e metal, solucionando grande número de problemas, tanto na indústria, como na agricultura, medicina e em outras áreas, devido a algumas características como durabilidade, atoxicidade, baixo custo, facilidade para ser moldado e versatilidade de aplicação ${ }^{[1]}$. No entanto, dentre os maiores problemas ambientais relacionados à utilização de materiais poliméricos, tais como o polipropileno, poliestireno, polietileno e poli(cloreto de vinila) destaca-se o tempo necessário para que ocorra degradação e a utilização de recursos não renováveis derivados do petróleo ${ }^{[2]}$. Neste contexto, o desenvolvimento de polímeros biodegradáveis vem surgindo como uma alternativa interessante.

Dentre os vários materiais biodegradáveis, podemos citar a família dos poli(hidroxialcanoatos), PHA’s, que são produzidos por uma ampla variedade de microrganismos como forma de reserva intracelular de carbono e energia ${ }^{[3]}$. A síntese de PHA por Cupriavidus necator requer a limitação de um nutriente essencial tal como o nitrogênio, 
fósforo, magnésio, potássio ou enxofre, e a presença de excesso de fonte de carbono ${ }^{[4-6]}$. Os PHAs produzidos por micro-organismos podem ser divididos em três classes: PHA de cadeia curta (PHA-SCL), contendo 3-5 átomos de carbono por monômero; PHA de cadeia média (PHA-MCL), polímeros constituídos por 6-14 átomos de carbono e polímeros com mais de 14 carbonos são considerados de cadeia longa (PHA-LCL); copolímeros contendo combinações dos monômeros de PHA-SCL e PHA-MCL são conhecidos como PHAs de cadeia mista ${ }^{[7,8]}$. Os micro-organismos sintetizam diferentes PHAs, compostos de vários tipos de monômeros dependendo das condições de cultivo e das fontes de carbono ${ }^{[9]}$, sendo capazes de produzir PHA a partir de várias fontes de carbono, tais como glicerol ${ }^{[10]}$, melaço de beterraba ${ }^{[11]}$ e óleos vegetais ${ }^{[8,12]}$.

A seleção da fonte de carbono é um fator importante que pode reduzir os custos de produção de PHA. As matérias-primas adequadas e relativamente baratas de carbono devem ser identificadas, a fim de maximizar a produção econômica de $\mathrm{PHA}^{[13]}$. Glicerol, uma fonte de carbono de baixo custo, é o principal subproduto da produção de biodiesel, que tem crescido exponencialmente nos últimos anos, devido ao aumento do uso de biocombustíveis, uma vez que a disponibilidade de petróleo é claramente limitada ${ }^{[14]}$. O glicerol é gerado a partir da transesterificação de gorduras e óleos vegetais ou animais ${ }^{[15]}$. Para cada $90 \mathrm{~m}^{3}$ de biodiesel produzidos por transesterificação são gerados, aproximadamente, $10 \mathrm{~m}^{3} \mathrm{de}$ glicerol bruto, o que reforça a necessidade de se encontrar utilizações comerciais para este coproduto do biodiesel ${ }^{[16]}$. Com o aumento da produção de biodiesel, o volume de glicerol bruto gerado tem crescido exponencialmente, com a consequente diminuição dos preços, o que afeta diretamente a economia biodiese ${ }^{[4]}$, por isso é necessária a busca de aplicações em grande escala para o excedente de glicerol gerado. Neste contexto, o objetivo deste estudo é avaliar a viabilidade da utilização de glicerol como cosubstrato para a produção de poli(3-hidroxibutirato) a partir de Cupriavidus necator.

\section{Materiais e Métodos}

\subsection{Micro-organismo}

O micro-organismo utilizado neste trabalho para a produção de $\mathrm{P}(3 \mathrm{HB})$ foi a bactéria Cupriavidus necator - DSM 545, mutante da linhagem DSM 529 H1 para consumo de glicose (anteriormente denominada Ralstonia eutropha), conforme definição proposta pela Deutsche Sammlung von Mikroorganismen und Zellkulturen GmbH ${ }^{[17]}$.

\subsection{Fonte de carbono}

Os experimentos foram realizados usando glicose (Synth, 99\% de pureza) e frutose (Synth, 99\% de pureza) (açúcar invertido) como fonte de carbono principal e glicerol puro (Synth, 86-88\% de pureza) como cosubstrato.

\subsection{Meio de cultura}

Caldo nutriente (NB) (Difco), contendo $5 \mathrm{~g} \mathrm{~L}^{-1}$ de extrato de peptona e $3 \mathrm{~g} \mathrm{~L}^{-1}$ de extrato de carne, foi usado como o meio de cultura de pré-cultura 1 e foi submetido a autoclave a $121{ }^{\circ} \mathrm{C}$ durante $20 \mathrm{~min}$. O meio de pré-cultura para 2 continha (por litro): $30 \mathrm{~g}$ da fonte de carbono (15 g de glicose e $15 \mathrm{~g}$ de frutose); $5 \mathrm{~g}\left(\mathrm{NH}_{4}\right)_{2} \mathrm{SO}_{4} ; 1,5 \mathrm{~g} \mathrm{KH}_{2} \mathrm{PO}_{4}$; $8,95 \mathrm{~g} \mathrm{Na}_{2} \mathrm{HPO}_{4} \cdot 12 \mathrm{H}_{2} \mathrm{O} ; 0,5 \mathrm{~g} \mathrm{MgSO}_{4} .7 \mathrm{H}_{2} \mathrm{O} ; 0,191 \mathrm{~g}$ ácido nitrilotriacético (NTA); $0,06 \mathrm{~g} \mathrm{C}_{6} \mathrm{H}_{11} \mathrm{FeNO}_{7}$ e $1 \mathrm{~mL}$ de solução de elementos traço. Para o meio de cultivo o meio inicial consistiu de $15 \mathrm{~g}$ glicose e $15 \mathrm{~g}$ frutose; $4 \mathrm{~g}\left(\mathrm{NH}_{4}\right)_{2} \mathrm{SO}_{4} ; 13,3 \mathrm{~g} \mathrm{KH}_{2} \mathrm{PO}_{4} ; 1,2 \mathrm{~g} \mathrm{MgSO}_{4} .7 \mathrm{H}_{2} \mathrm{O} ; 1,87 \mathrm{~g}$ de ácido cítrico e $10 \mathrm{~mL}$ solução de elementos traço. A solução de elementos traço para o meio de pré-cultura 2 e para os experimentos em biorreator continha (por litro): $0,3 \mathrm{~g} \mathrm{H}_{3} \mathrm{BO}_{3} ; 0,2 \mathrm{~g} \mathrm{CoCl}_{2} .6 \mathrm{H}_{2} \mathrm{O} ; 0,1 \mathrm{~g} \mathrm{ZnSO} 4.7 \mathrm{H}_{2} \mathrm{O} ; 0,03 \mathrm{~g}$ $\mathrm{MnCl}_{2} \cdot 4 \mathrm{H}_{2} \mathrm{O} ; 0,03 \mathrm{~g} \mathrm{Na}_{2} \mathrm{MoO}_{4} \cdot 2 \mathrm{H}_{2} \mathrm{O} ; 0,02 \mathrm{~g} \mathrm{NiCl}_{2} \cdot 6 \mathrm{H}_{2} \mathrm{O}$; $0,01 \mathrm{~g} \mathrm{CuSO}_{4} \cdot 5 \mathrm{H}_{2} \mathrm{O}$. A fonte de carbono e a solução que consistia de $\mathrm{Na}_{2} \mathrm{HPO}_{4}$ e $\mathrm{KH}_{2} \mathrm{PO}_{4}$ foram autoclavadas separadamente a $121^{\circ} \mathrm{C}$ durante $20 \mathrm{~min}$, e após resfriamento foram assepticamente misturadas; $\mathrm{o} \mathrm{pH}$ do meio foi ajustado em 6.8 com solução $5 \mathrm{M} \mathrm{NaOH}$ e $11 \mathrm{M} \mathrm{HCl}$.

\subsection{Inóculo}

As células foram armazenadas a $-80^{\circ} \mathrm{C}$ em microtubos de $2 \mathrm{~mL}$, contendo $500 \mu \mathrm{L}$ de meio de cultura em fase líquida e $500 \mu \mathrm{L}$ de uma solução de glicerol comercial a $40 \%$. Para os cultivos, as células foram transferidas para frascos Erlenmeyer $(500 \mathrm{~mL})$ contendo $100 \mathrm{~mL}$ de caldo $\mathrm{NB}$ (pré-cultura 1) e incubadas a $30{ }^{\circ} \mathrm{C}$ em um shaker orbital (B. Braun - Certomat) a $150 \mathrm{~min}^{-1}$, durante um período de 16-18h. A pré-cultura 2, usada para inocular os experimentos em biorreator, foi cultivada em $300 \mathrm{~mL}$ de meio de cultura (em frascos de $1000 \mathrm{~mL}$ ), inoculado com $30 \mathrm{~mL}$ da pré-cultura 1 e incubado por $24 \mathrm{~h}$, a $30{ }^{\circ} \mathrm{C}$ e $150 \mathrm{~min}^{-1}$.

\subsection{Experimentos em biorreator}

Os experimentos foram realizados em recipiente de cultivo de 2L B. Braun, acoplado a Biostat B. Após a inoculação de $10 \%(\mathrm{v} / \mathrm{v})$ da pré-cultura 2 no meio de cultura, o volume do biorreator atingiu 1,5 L e foi mantido durante período de 72 horas em processo de batelada alimentada; temperatura e $\mathrm{pH}$ foram controladas a $37^{\circ} \mathrm{C}$ e 6,8 , respectivamente. $\mathrm{O} \mathrm{pH}$ foi controlado utilizando $\mathrm{NaOH}(5 \mathrm{~N})$ e solução de $40 \%$ de $\mathrm{HCl}(\mathrm{v} / \mathrm{v})$. As condições de agitação e aeração variaram de 450-700 $\mathrm{min}^{-1}$. Três experimentos em batelada alimentada foram realizados (em duplicata) sob as seguintes condições: cultivo sem adição de glicerol (SG); cultura com adição de $20 \mathrm{~g} \mathrm{~L}^{-1}$ de glicerol puro na fase de produção de polímero (AG-FP) (quando ocorre a limitação de nitrogênio) e cultivo com a adição de $20 \mathrm{~g} \mathrm{~L}^{-1}$ de glicerol puro no início do cultivo (AG-IC). O final da fase de crescimento celular e, portanto, início da fase de produção do polímero, foi definido no momento em que houve exaustão de nitrogênio. Em cada ensaio realizado uma solução contendo fonte de nitrogênio e de fosfatos foi adicionada duas vezes ao biorreator, sempre que a concentração de nitrogênio se aproximava da exaustão com o objetivo de aumentar a concentração celular na fase de crescimento. A solução alimentada tinha a seguinte concentração: 3,45 g de sulfato de amônio; 5,4 g de $\mathrm{Na}_{2} \mathrm{HPO}_{4} ; 12 \mathrm{H}_{2} \mathrm{O}$ e $6 \mathrm{~g}$ de $\mathrm{KH}_{2} \mathrm{PO}_{4}$, em $20 \mathrm{~mL}$ de água. Sempre que a concentração de substrato se aproximou de $10 \mathrm{~g} \mathrm{~L}^{-1}$ foi realizada a adição de uma solução concentrada de açúcar invertido, de forma a permitir que a concentração de substrato retornasse a um valor entre 30 e $40 \mathrm{~g} \mathrm{~L}^{-1}$. 
O consumo de substrato foi monitorado pelo método de ácido 3,5-dinitrosalić́lico (DNS) ${ }^{[18]}$.

\subsection{Determinação da biomassa}

A biomassa foi acompanhada por gravimetria, com o uso de microtubos de centrifugação (Eppendorf). Os tubos foram previamente secos em estufa da marca WTC Binder a $60{ }^{\circ} \mathrm{C}$ por $24 \mathrm{~h}$ e pesados em balança analítica da marca Mettler AT250. Alíquotas de $2 \mathrm{~mL}$ da amostra foram colocadas nesses tubos e centrifugadas a $9000 \mathrm{rpm}$ por $10 \mathrm{~min}(6.610 \mathrm{~g})$. Em seguida, o meio foi descartado e as células foram lavadas duas vezes com água destilada. A água foi retirada após nova centrifugação e as células secas em estufa a $60{ }^{\circ} \mathrm{C}$ até massa constante. Essa massa foi então convertida em concentração celular expressa em $\mathrm{g} \mathrm{L}^{-1}$.

\subsection{Quantificação do consumo de glicerol}

O consumo de glicerol foi determinado por cromatografia líquida de alta eficiência (HPLC) (Merck Hitachi modelo D-7000IF) com detector de índice de refração modelo RI-71 Merck, com a coluna de marca Transgenomic, modelo ICSep ICE-ION Column (trocadora de prótons). A fase móvel utilizada foi $\mathrm{H}_{2} \mathrm{SO}_{4} 8,5 \mathrm{mmol} \mathrm{L}^{-1}$ tendo fluxo de eluente de $0,4 \mathrm{~mL} \mathrm{~min}{ }^{-1}$ e temperatura do forno de $70{ }^{\circ} \mathrm{C}$ com volume de injeção de $10 \mu \mathrm{L}$. As amostras foram coletadas e centrifugadas em uma microcentrífuga a $6.600 \mathrm{~g}$ por $10 \mathrm{~min}$. O sobrenadante foi diluído (1:8) com água destilada e centrifugado a $6.600 \mathrm{~g}$ por $10 \mathrm{~min}$. As amostras diluídas foram filtradas in filtros de PTFE de $0,45 \mu \mathrm{m}$. O volume de injeção foi de $10 \mu \mathrm{L}$.

\subsection{Determinação da concentração de $P(3 H B)$}

Para a quantificação de $\mathrm{P}(3 \mathrm{HB})$, tubos de Eppendorf contendo $2 \mathrm{~mL}$ de amostra foram centrifugados a $6.600 \mathrm{~g}$ por $10 \mathrm{~min}$. O sobrenadante foi descartado e as células foram ressuspensas com água destilada e centrifugadas novamente. As células foram transferidas para tubos de ensaio, aos quais acrescentou-se $2 \mathrm{~mL}$ de metanol acidificado ( $15 \%$ de ácido sulfúrico e ácido benzóico na concentração de $0,4 \mathrm{~g} \mathrm{~L}^{-1}$ ) e $2 \mathrm{~mL}$ de clorofórmio. Os tubos de ensaio foram vedados com fita veda-rosca, e em seguida levados ao banho termostático, com tampa, a $100^{\circ} \mathrm{C}$, durante 1 hora. Decorrido este tempo, os tubos de ensaio foram retirados e agitados em vórtex, voltando ao banho por mais $1 \mathrm{~h} 20 \mathrm{~min}$. Finalmente, os tubos foram retirados do banho quente e levados a um banho de gelo para interromper a reação. Após resfriamento das amostras acrescentou-se $1 \mathrm{~mL}$ de água milli-Q, agitando-se novamente no vórtex durante 30 segundos para a formação de duas fases. Com o auxílio de uma pipeta Pasteur, retirou-se a fase inferior (clorofórmio e polímero) passando-a a viels previamente identificados para a análise por cromatografia gasosa (CG). Após a metanólise, a concentração de polímero contida nas células foi analisada por cromatografia gasosa. Para tanto, utilizou-se um cromatógrafo CG-System 6890 da Agilent, equipado com detector de ionização de chama (FID - hidrogênio e oxigênio). $\mathrm{O}$ gás de arraste utilizado foi hélio a $3,5 \mathrm{~mL} \mathrm{~min}^{-1}$ a fluxo constante e a temperatura de injeção e detecção foi de $250{ }^{\circ} \mathrm{C}$ e para a coluna utilizou-se rampa de temperatura de 80 a $200{ }^{\circ} \mathrm{C}\left(20^{\circ} \mathrm{C} \mathrm{min}^{-1}\right)$. Utilizou-se uma coluna de sílica fundida (Ø $0,53 \mathrm{~mm} / 30 \mathrm{~m})$ modelo Supercowax 10 .

\section{Resultados e Discussão}

Na Tabela 1 estão relacionados os dados cinéticos dos ensaios em biorreator, sendo que para cada ensaio está apresentada a média e o desvio padrão.

Na Figura 1 estão ilustradas as curvas cinéticas dos cultivos realizados em meio sem adição de glicerol (SG), com adição de $20 \mathrm{~g} \mathrm{~L}^{-1}$ de glicerol na fase de produção do polímero (AG-FP) e com adição de $20 \mathrm{~g} \mathrm{~L}^{-1}$ de glicerol no início do cultivo (AG-IC), respectivamente. Os pontos representados nos gráficos correspondem aos valores experimentais de biomassa total $(\mathrm{Xt})$, biomassa residual (Xr) e concentração de $\mathrm{P}(3 \mathrm{HB})$, e as curvas apresentadas foram obtidas por ajuste polinomial dos dados experimentais. É possível observar, analisando os resultados das curvas de biomassa residual $(\mathrm{Xr}=\mathrm{Xt}-\mathrm{P}(3 \mathrm{HB}))$ de todos os cultivos, que o aumento da biomassa celular ocorreu até a limitação em nitrogênio (representada pela linha tracejada vertical). Após a limitação em nitrogênio as células praticamente pararam de crescer e passaram a acumular $\mathrm{P}(3 \mathrm{HB})$ de forma intracelular, comportamento característico de Cupriavidus necator que já foi observado por outros autores como Cavalheiro et al. ${ }^{[15]} \mathrm{e}$ Lee et al. ${ }^{[19]}$. A adição de glicerol não favoreceu o acúmulo total de $\mathrm{P}(3 \mathrm{HB})$ e de biomassa, uma vez que os valores obtidos foram muito semelhantes em todos os cultivos. No entanto, a adição de glicerol no início do cultivo levou a maiores valores de percentual de acúmulo de $\mathrm{P}(3 \mathrm{HB})$ em relação aos ensaios sem adição de glicerol ou quando

Tabela 1. Valores de biomassa total (Xt), biomassa residual (Xr), concentração de $\mathrm{P}(3 \mathrm{HB})$, acúmulo (\%) de $\mathrm{P}(3 \mathrm{HB})$, fator de conversão de substrato em célula $\left(\mathrm{Y}_{\mathrm{Xr} / \mathrm{S}}\right)$, fator de conversão de substrato em produto $\left(\mathrm{Y}_{\mathrm{P}(3 \mathrm{HB}) \mathrm{S}}\right)$ e produtividade em polímero $\left(\mathrm{Pg}_{\mathrm{P}(3 \mathrm{HB})}\right)$.

\begin{tabular}{|c|c|c|c|c|c|c|}
\hline \multirow{2}{*}{ Parâmetro cinético } & \multicolumn{2}{|c|}{ SG } & \multicolumn{2}{|c|}{ AG-FP } & \multicolumn{2}{|c|}{ AG-IC } \\
\hline & Média & DP* & Média & DP* & Média & DP* \\
\hline $\mathrm{Xt}\left(\mathrm{g} \mathrm{L}^{-1}\right)$ & 39,19 & 4,02 & 35,60 & 2,19 & 38,33 & 2,44 \\
\hline $\mathrm{Xr}\left(\mathrm{g} \mathrm{L}^{-1}\right)$ & 17,65 & 1,64 & 14,31 & 0,65 & 12,48 & 1,13 \\
\hline $\mathrm{P}(3 \mathrm{HB})\left(\mathrm{g} \mathrm{L}^{-1}\right)$ & 21,54 & 2,38 & 21,29 & 1,54 & 24,58 & 1,79 \\
\hline Acúmulo $\mathrm{P}(3 \mathrm{HB})(\%)$ & 54,93 & 0,46 & 59,83 & 0,58 & 64,12 & 0,56 \\
\hline $\mathrm{Y}_{\mathrm{Xr} / \mathrm{S}}\left(\mathrm{g} \mathrm{g}^{-1}\right)$ & 0,17 & 0,002 & 0,12 & 0,01 & 0,12 & 0,002 \\
\hline $\mathrm{Y}_{\mathrm{P}(3 \mathrm{HB}) / \mathrm{S}}\left(\mathrm{g} \mathrm{g}^{-1}\right)$ & 0,22 & 0,010 & 0,20 & 0,005 & 0,22 & 0,013 \\
\hline $\operatorname{Pg}_{\mathrm{P}(3 \mathrm{HB})}\left(\mathrm{g} \mathrm{L}^{-1} \mathrm{~h}^{-1}\right)$ & 0,30 & 0,035 & 0,30 & 0,021 & 0,34 & 0,025 \\
\hline
\end{tabular}

*Desvio padrão. 

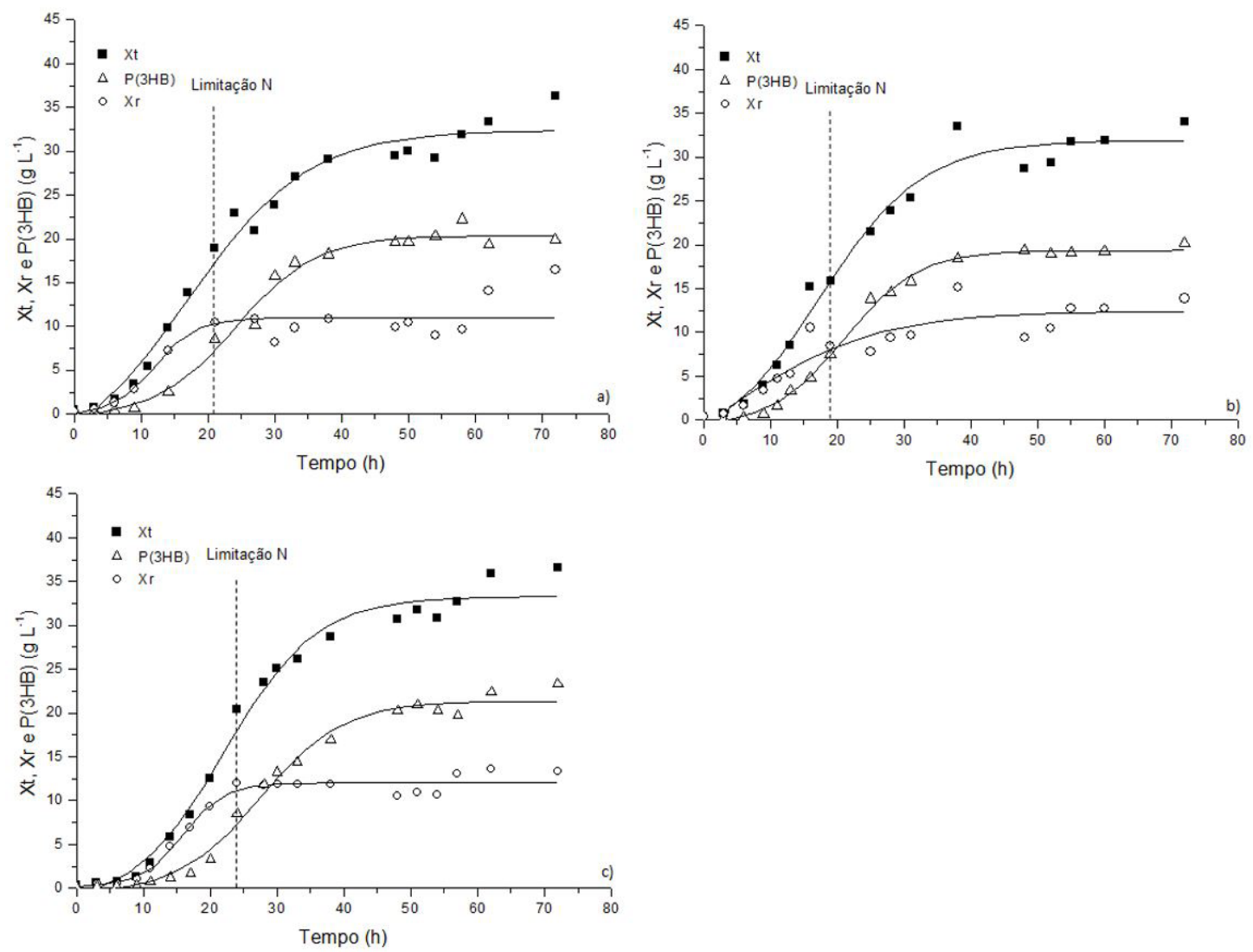

Figura 1. Cinética de crescimento de Cupriavidus necator e produção de $\mathrm{P}(3 \mathrm{HB})$ em: (a) cultivo realizado sem glicerol (SG); (b) cultivo com adição de $20 \mathrm{~g} \mathrm{~L}^{-1}$ de glicerol na fase de produção do polímero (AG-FP) cultivo e (c) cultivo com adição de $20 \mathrm{~g} \mathrm{~L}^{-1}$ de glicerol no início do cultivo (AG-IC).

o glicerol foi adicionado somente na fase de produção do polímero; para os cultivos AG-IC os valores foram de $64,12 \%$; acúmulo de 59,83\% para os cultivos AG-FP e 54,93\% para os cultivos SG. Os valores de $\mathrm{Pg}_{\mathrm{P}(3 \mathrm{HB})}$ foram muito similares (entre 0,30 e 0,34 ; Tabela 1 ). Cavalheiro et al. ${ }^{[15]}$ cultivando $C$. necator em batelada alimentada, chegaram a uma produtividade $1,52 \mathrm{~g} \mathrm{~L}^{-1} \mathrm{~h}^{-1}$ utilizando glicerol puro (a concentração celular chegou a 82,5 $\mathrm{g} \mathrm{L}^{-1}$, com acúmulo de $62 \%$ de polímero) e de $0,84 \mathrm{~g} \mathrm{~L}^{-1} \mathrm{~h}^{-1}$ a partir de glicerol bruto (a concentração máxima de células foi de $68,8 \mathrm{~g} \mathrm{~L}^{-1}$, com acúmulo de $38 \%$ ). Mothes et al. ${ }^{[20]}$ também reportaram uma redução do conteúdo de $\mathrm{P}(3 \mathrm{HB})$ de $70 \%$ (obtido a partir de glicerol puro) para $48 \%$ quando glicerol bruto (com pureza de $80 \%$ contendo $5,5 \%$ de $\mathrm{NaCl}$ ) foi utilizado em cultivos a partir de C. necator JMP 134. Kachrimanidou et al. ${ }^{[21]}$ cultivaram C. necator DSM 7237 utilizando glicerol bruto ( $92,4 \% \mathrm{~m} / \mathrm{m}$ de pureza) como fonte de carbono e hidrolisado de farinha de girassol como fonte de nitrogênio e obtiveram concentração de $\mathrm{P}(3 \mathrm{HB})$ de $24,6 \mathrm{~g} \mathrm{~L}^{-1}$ (com biomassa total de $\left.32,2 \mathrm{~g} \mathrm{~L}^{-1}\right)$, conteúdo de $\mathrm{P}(3 \mathrm{HB})$ de $76,4 \%$, produtividade de $0,31 \mathrm{~g} \mathrm{~L}^{-1} \mathrm{~h}^{-1}$ e fator de conversão de $0,30 \mathrm{~g}$ de $\mathrm{P}(3 \mathrm{HB})$ por $\mathrm{g}$ de glicerol consumido.

Na Figura 2 estão apresentados os valores de fator de conversão global de substrato em biomassa residual. Nos ensaios com adição de glicerol foi possível observar

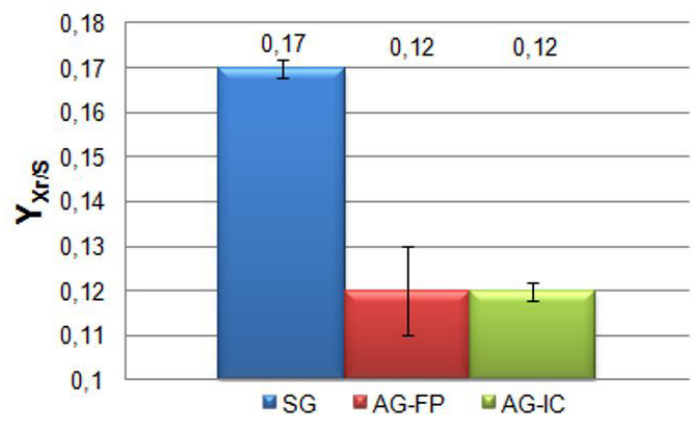

Figura 2. Fator de conversão global de substrato em biomassa residual para os experimentos sem glicerol (SG), com adição de glicerol na fase de produção do polímero (AG-FP) e com adição de glicerol no início do cultivo (AG-IC).

os menores valores de fator de conversão de substrato em biomassa residual $\left(\mathrm{Y}_{\mathrm{Xr} / \mathrm{S}}\right)$, tanto para AG-FP quanto para AG-IC esses valores foram $0,12 \mathrm{~g} \mathrm{~g}^{-1}$, enquanto que nos ensaios sem adição de glicerol foi possível observar valores de $\mathrm{Y}_{\mathrm{Xr} / \mathrm{S}}$ de $0,17 \mathrm{~g} \mathrm{~g}^{-1}$, o que indica que a utilização apenas de açúcar invertido como fonte de carbono favorece a conversão de substrato em biomassa residual. 
Tabela 2. Teste $t$ de Student para fator de conversão de substrato em biomassa residual $\left(\mathrm{Y}_{\mathrm{Xr} / \mathrm{S}}\right)$.

\begin{tabular}{lcccccc}
\hline \multicolumn{1}{c}{ Variável } & Média & Desvio padrão & N & $\begin{array}{c}\text { Graus de } \\
\text { liberdade }\end{array}$ & F & p (<0,05) \\
\hline SG & 0,1751 & 0,003 & 2 & 2 & 6,534 & $\mathbf{0 , 0 2 2 6}$ \\
AG-FP & 0,1251 & 0,01 & & 2 & 22,211 & $\mathbf{0 , 0 0 2 0}$ \\
SG & 0,1751 & 0,003 & 2 & & & 0,4707 \\
AG-IC & 0,1185 & 0,002 & & 2 & 0,882 & \\
AG-FP & 0,1251 & 0,01 & 2 & & & \\
AG-IC & 0,1185 & 0,002 & & & & \\
\hline
\end{tabular}

Tabela 3. Teste $\mathrm{t}$ de Student para acúmulo de $\mathrm{P}(3 \mathrm{HB})(\%)$.

\begin{tabular}{lcccccc}
\hline \multicolumn{1}{c}{ Variável } & Média & Desvio padrão & N & $\begin{array}{c}\text { Graus de } \\
\text { liberdade }\end{array}$ & F & p (<0,05) \\
\hline AG-FP & 59,83 & 0,5798 & 2 & 2 & 9,356 & $\mathbf{0 , 0 1 1 2 3 2}$ \\
SG & 54,953 & 0,4596 & & 2 & 17,821 & $\mathbf{0 , 0 0 3 1 3 4}$ \\
AG-IC & 64,12 & 0,5657 & 2 & & \\
SG & 54,953 & 0,4596 & & 2 & 7,489 & $\mathbf{0 , 0 1 7 3 6 5}$ \\
AG-IC & 64,12 & 0,5657 & 2 & & \\
AG-FP & 59,83 & 0,5798 & & & & \\
\hline
\end{tabular}

Para avaliar a influência das diferentes estratégias de cultivo de Cupriavidus necator foi realizada uma análise estatística dos parâmetros cinéticos obtidos nesse estudo. A análise estatística foi avaliada pelo software Statistica 7 e a ferramenta utilizada foi o teste-t de Student (para duas amostras independentes). Nas Tabelas 2 e 3 estão apresentadas as análises do teste-t para fator de conversão de substrato em biomassa residual $\left(\mathrm{Y}_{\mathrm{Xr} / \mathrm{S}}\right)$, para o acúmulo percentual de $\mathrm{P}(3 \mathrm{HB})$ para produtividade de $\mathrm{P}(3 \mathrm{HB})$ na fase de produção do polímero, respectivamente. Para cada variável e suas interações estão demonstradas a média, o desvio padrão, o número de amostras $(\mathrm{N})$, o grau de liberdade, o F calculado e a probabilidade dos valores serem significativos $(p<0,05)$.

Para o $\mathrm{Y}_{\mathrm{Xr} / \mathrm{S}}$, verificou-se, pela estimativa do $\mathrm{p}$-valor fornecido pelo teste-t de Student, que os resultados são considerados estatisticamente significativos para o cultivo SG em relação ao cultivo AG-FP e também para o cultivo SG em relação ao cultivo AG-IC, enquanto que para os dois cultivos em que houve adição de glicerol não foi observada diferença significativa para o parâmetro $\mathrm{Y}_{\mathrm{Xr} / \mathrm{S}}$. No entanto, para o acúmulo de $\mathrm{P}(3 \mathrm{HB})(\%)$, pode-se observar que os resultados obtidos pelas diferentes estratégias de cultivo (SG, AG-FP e AG-IC) são considerados estatisticamente significativos para as três variáveis, sendo que os melhores resultados foram obtidos quando se adicionou glicerol no início do cultivo celular.

\section{Conclusões}

A utilização de glicerol como cosubstrato mostrou-se viável, uma vez que o glicerol foi consumido durante o cultivo. Os parâmetros cinéticos de produtividade foram muito semelhantes para todos os cultivos, bem como a produção de $\mathrm{P}(3 \mathrm{HB})$. No entanto, a percentagem de acúmulo de $\mathrm{P}(3 \mathrm{HB})$ foi mais elevada para o ensaio com adição de glicerol no início do cultivo e o fator de conversão de substrato em biomassa $\left(\mathrm{Y}_{\mathrm{Xr} / \mathrm{S}}\right)$ foi maior para as culturas nas quais não houve adição de glicerol, indicando que a presença de glicerol favorece o percentual de acúmulo intracelular de polímero. Os parâmetros cinéticos que mostraram diferenças estatisticamente significativas foram $\mathrm{Y}_{\mathrm{Xr} / \mathrm{S}}$, com melhores resultados para o cultivo sem glicerol (SG) e acúmulo de $\mathrm{P}(3 \mathrm{HB})(\%)$, com resultados mais significativos para a condição em que o glicerol foi introduzido no início de cultivo (AG-IC).

\section{Agradecimentos}

Gostaríamos de agradecer a Universidade da Região de Joinville-UNIVILLE e a Coordenação de Aperfeiçoamento de Pessoal de Nível Superior - CAPES pelo apoio financeiro.

\section{Referências}

1. Faria, A. U., \& Franchetti, S. M. M. (2010). Biodegradação de filmes de polipropileno (PP), poli(3-hidroxibutirato) (PHB) e blenda de PP/PHB por microrganismos das águas do Rio Atibaia. Polímeros: Ciência e Tecnologia, 20(2), 141-147. http://dx.doi.org/10.1590/S0104-14282010005000024.

2. Vogelsanger, N., Formolo, M. C., Pezzin, A. P. T., Schneider, A. L. S., Furlan, S. A., Bernardo, H. P., Pezzin, S. H., Pires, A. T. N., \& Duek, E. A. R. (2003). Blendas biodegradáveis de Poli(3-Hidroxibutirato)/Poli(ع-Caprolactona): obtenção e estudo da miscibilidade. Materials Research, 6(3), 359-365. http://dx.doi.org/10.1590/S1516-14392003000300010.

3. Roa, J. P. B., Mano, V., Faustino, P. B., Felix, E. B., Ribeiro e Silva, M. E. S., \& Souza, J. D., Fo (2010). Síntese e caracterização do copolímero poli(3-hidroxibutirato-co- $\varepsilon$-caprolactona) a partir de poli(3-hidroxibutirato) e poli(e-caprolactona). Polímeros: Ciência e Tecnologia, 20(3), 221-226. http://dx.doi.org/10.1590/ S0104-14282010005000038.

4. Posada, J. A., Naranjo, J. M., López, J. A., Higuita, J. C., \& Cardona, C. A. (2011). Design and analysis of poly-3hydroxybutyrate production processes from crude glycerol. Process Biochemistry, 46(1), 310-317. http://dx.doi.org/10.1016/j. procbio.2010.09.003. 
5. Khanna, S., \& Srivastava, A. K. (2005). Recent advances in microbial polyhydroxyalkanoates. Process Biochemistry, 40(2), 607-619. http://dx.doi.org/10.1016/j.procbio.2004.01.053.

6. García, I. L., López, J. A., Dorado, M. P., Kopsahelis, N., Alexandri, M., Papanikolaou, S., Villar, M. A., \& Koutinas, A. A. (2013). Evaluation of by-products from the biodiesel industry as fermentation feedstock for poly(3-hydroxybutyrateco-3-hydroxyvalerate) production by Cupriavidus necator. Bioresource Technology, 130, 16-22. PMid:23280181. http:// dx.doi.org/10.1016/j.biortech.2012.11.088.

7. Suriyamongkol, P., Weselake, R., Narine, S., Moloney, M., \& Shah, S. (2007). Biotechnological approaches for the production of polyhydroxyalkanoates in microorganisms and plants: a review. Biotechnology Advances, 25(2), 148-175. PMid:17222526. http://dx.doi.org/10.1016/j.biotechadv.2006.11.007.

8. Wong, Y.-M., Brigham, C. J., Rha, C. K., Sinskey, A. J., \& Sudesh, K. (2012). Biosynthesis and characterization of polyhydroxyalkanoate containing high 3-hydroxyhexanoate monomer fraction from crude palm kernel oil by recombinant Cupriavidus necator. Bioresource Technology, 121, 320-327. PMid:22858502.http://dx.doi.org/10.1016/j.biortech.2012.07.015.

9. Chai, H.-L., Ahmad, R., Yahya, A. R. M., Majid, M. I. A., \& Amirul, A. A. (2009). Microbial synthesis of poly (3-hydroxybutyrate-co-4-hydroxybutyrate) copolymer by Cupriavidus sp USMAA2-4 through a two-step cultivation process. African Journal of Biotechnology, 8(17), 4189-4196.

10. Cavalheiro, J. M. B. T., Raposo, R. S., Almeida, M. C. M. D., Cesário, M. T., Sevrin, C., Grandfils, C., \& Fonseca, M. M. R. (2012). Effect of cultivation parameters on the production of poly(3-hydroxybutyrate-co-4-hydroxybutyrate) and poly(3hydroxybutyrate-4-hydroxybutyrate-3-hydroxyvalerate) by Cupriavidus necator using waste glycerol. Bioresource Technology, 111, 391-397. PMid:22382294. http://dx.doi. org/10.1016/j.biortech.2012.01.176.

11. Page, W. J. (1992). Production of PHA by Azotobacter vinelandii UWD in beet molasses culture. FEMS Microbiology Letters, 103, 144-158. http://dx.doi.org/10.1111/j.1574-6968.1992. tb05832.x.

12. Fukui, T., \& Doi, Y. (1998). Efficient production of polyhydroxyalkanoates from plant oils by Alcaligenes eutrophus and its recombinant strain. Applied Microbiology and Biotechnology, 49(3), 333-336. PMid:9581296. http:// dx.doi.org/10.1007/s002530051178.

13. Tanadchangsaeng, N., \& Yu, J. (2012). Microbial synthesis of polyhydroxybutyrate from glycerol: gluconeogenesis, molecular weight and material properties of biopolyester. Biotechnology and Bioengineering, 109(11), 2808-2818. PMid:22566160. http://dx.doi.org/10.1002/bit.24546.

14. Silva, G. P., Mack, M., \& Contiero, J. (2009). Glycerol: a promising and abundant carbon source for industrial microbiology. Biotechnology Advances, 27(1), 30-39. PMid:18775486. http:// dx.doi.org/10.1016/j.biotechadv.2008.07.006.

15. Cavalheiro, J. M. B. T., Almeida, M. C. M. D., Grandfils, C., \& Fonseca, M. M. R. (2009). Poly(3-hydroxybutyrate) production by Cupriavidus necator using waste glycerol. Process Biochemistry, 44(5), 509-515. http://dx.doi.org/10.1016/j. procbio.2009.01.008.

16. Mota, C. J. A., Silva, C. X. A., \& Gonçalves, V. L. C. (2009). Gliceroquímica: novos produtos e processos a partir da Glicerina de produção de biodiesel. Quimica Nova, 32(3), 639-648. http://dx.doi.org/10.1590/S0100-40422009000300008.

17. Leibniz-Institute DSMZ-Deutsche Sammlung von Mikroorganismen und Zellkulturen. (2015). Recuperado em 02 de fevereiro de 2015, de http://www.dsmz.de/catalogues/details/culture/DSM545.html?tx_dsmzresources_pi5\%5BreturnPid\%5D=304

18. Miller, G. L. (1959). Use of dinitrosalicilic acid reagent for determination of reducing sugar. Analytical Chemistry, 31(3), 426-428. http://dx.doi.org/10.1021/ac60147a030.

19. Lee, S. Y., Choi, J., \& Wong, H. H. (1999). Recent advances in polyhydroxyalkanoate production by bacterial fermentation: mini-review. International Journal of Biological Macromolecules, 25(1-3), 31-36. PMid:10416647. http://dx.doi.org/10.1016/ S0141-8130(99)00012-4.

20. Mothes, G., Schnorpfeil, C., \& Ackermann, J.-U. (2007). Production of PHB from Crude Glycerol. Engineering in Life Sciences, 7(5), 475-479. http://dx.doi.org/10.1002/ elsc.200620210.

21. Kachrimanidou, V., Kopsahelis, N., Papanikolaou, S., Kookos, I. K., De Bruyn, M., Clark, J. H., \& Koutinas, A. A. (2014). Sunflower-based biorefinery: Poly(3-hydroxybutyrate) and poly(3-hydroxybutyrate-co-3-hydroxyvalerate) production from crude glycerol, sunflower meal and levulinic acid. Bioresource Technology, 172, 121-130. PMid:25255188. http:// dx.doi.org/10.1016/j.biortech.2014.08.044.

Enviado: Jul. 07, 2015

Revisado: Fev. 17, 2016

Aceito: Jun. 08, 2016 